\title{
Avante Luta Antimanicomial, ocupemos os planos diretores das cidades
}

\author{
Onward with the Anti-asylum Struggle, occupying city master plans
}

Gitonam Lucas Tavares Honorato (https://orcid.org/0000-0003-0422-2199) ${ }^{1}$

${ }^{1}$ Programa de Pós-

Graduação em Geografia, Universidade Federal Fluminense. Rua Gal. Milton Tavares s/n Instituto de Geociências, Campus Praia Vermelha Boa Viagem. 24210-346 Niterói RJ Brasil. lucasthonorato@ yahoo.com.br

\begin{abstract}
This article reflects on the limits and possibilities for articulating the anti-asylum struggle with participatory city master plans (PMPs) in Brazil with the aim of helping enhance anti -asylum care in liberty and guaranteeing the rights of people experiencing mental suffering. Departing from the premise that the city is neither a therapeutic nor a caring environment, this analysis seeks to weave together the challenges of "living in liberty" with urban planning policies guided by PMPs. To this end, we analyzed terms pertaining to the anti-asylum struggle and Brazil's mental health reform in the PMPs of the 15 highest-scoring cities in the Connected Smart Cities Ranking. The findings show that it is important for the anti -asylum struggle to dispute municipal urban policies in wider legislative arenas in order to promote further advances in deinstitutionalization and a transformation of the social place of madness, and guarantee the rights of people experiencing mental suffering in cities.
\end{abstract}

Key words Citizenship, Deinstitutionalization, Social participation, City planning, Mental health
Resumo O presente artigo reflete sobre os limites e possibilidades de articulação entre a Luta Antimanicomial e os Planos Diretores Participativos das cidades (PDPs) no Brasil, com vistas ao cuidado antimanicomial em liberdade para as pessoas em sofrimento mental, bem como à garantia de realização e à ampliação dos seus direitos. Ao partir da premissa de que a cidade não é por si terapêutica nem tampouco cuidadora, desenvolvemos uma analítica que busca entrecruzar os desafios do "morar em liberdade" com as politicas de desenvolvimento urbano nos municípios brasileiros - estas, orientadas pelos PDPs. Assim, analisamos citações concernentes ao temário da Luta Antimanicomial e Reforma Psiquiátrica Brasileira (RPB) nos PDPs dos 15 municípios mais bem avaliados no ranking de qualidade urbana nacional, de acordo com a Plataforma Connected Smart Cities. Com base nessa pesquisa, pudemos refletir sobre a importância de a Luta Antimanicomial disputar as politicas urbanas municipais para articular, em arenas ainda mais ampliadas na via legislativa, avanços nos termos da desinstitucionalização, transformação do lugar social da loucura e realização dos direitos de cidadania para pessoas em situação de sofrimento mental nas cidades.

Palavras-chave Cidadania, Desinstitucionalização, Participação social, Planejamento das cidades, Saúde mental 


\section{Introdução}

Ao longo de quase 20 anos de institucionalização da Reforma Psiquiátrica Brasileira (RPB), a partir da Lei no 10.216/2001 e outras normativas subsequentes ${ }^{1,2}$, pudemos notar avanços significativos em relação à reorganização do cuidado com as pessoas em situação de sofrimento mental no país. Os processos de desospitalização, construção de serviços extra-hospitalares e organização de Redes de Atenção Psicossocial (RAPS) ilustram importantes vitórias para o avanço da Luta Antimanicomial, sobretudo em relação à desinstitucionalização das pessoas em sofrimento men$\mathrm{tal}^{3}$ e à consolidação do paradigma da Atenção Psicossocial no Brasilit,

Antagônica à perspectiva biomédica e hospitalocêntrica, o paradigma da atenção psicossocial busca outras estratégias de cuidado, com base na criação e fortalecimento de vínculos, na afirmação da diferença e na produção de saúde ${ }^{5}$. Em oposição ao processo diagnóstico-medicalização-cura, afirma-se a diferença-liberdade-vida.

Em termos espaciais e a contrapelo das históricas práticas de sequestro social, a perspectiva da desinstitucionalização aposta na cidade, lugar da multiplicidade e da diferença, para a potencialização da vida daqueles sujeitos em sofrimento - a cidade como lócus da transformação do lugar social da loucura. Em síntese, esta abordagem se propõe como uma inflexão nas práticas e sentidos da Saúde Mental, que pode ser sintetizada nos seguintes termos: "do manicômio, lugar zero dos intercâmbios sociais, à multiplicidade extrema das relações sociais"' (p. 36).

Tendo a cidade como centralidade terapêutica e o "morar em liberdade" como condição sine qua non para a transdução do sujeito-sujeitado em sujeito-cidadão, o existir, o habitar e o viver a cidade colocam questões desafiadoras para as pessoas em sofrimento mental, não apenas no que tange à prática clínica, como também em relação às possibilidades concretas de realização efetiva de sua cidadania". Se, por um lado, "o paciente se torna cidadão de pleno direito e muda, com isto, sua contratualidade em relação à socie-

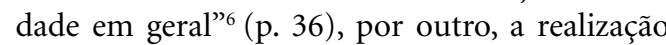
desses direitos de cidadania (sociais, políticos e humanos) rebatem em outros entraves não restritos à arena jurídico-normativa, mas associados ao enfrentamento de todo um conjunto estrutural de distâncias, desigualdades socioespaciais e geografias de exclusão e opressões, que marcam a realidade cotidiana das cidades brasileiras.

Enquanto cerne da questão social e esfera de (re)produção das desigualdades e injustiças, mas também das lutas e da emancipação $0^{8}$, os territórios na cidade acabam circunscrevendo possibilidades diferentes e desiguais aos diversos sujeitos sociais no tocante ao acesso aos direitos e serviços essenciais à vida social e individual. Nesse sentido, há de se considerar o processo histórico de uma urbanização capitalista na conformação dos territórios das cidades brasileiras, distribuindo os recursos sociais urbanos de forma desigual e combinada ${ }^{9,10}$. Fundado no e para a produção e o consumo, o ordenamento espacial capitalista, é, portanto, mais um desafio à cidadania, por ser ao mesmo tempo produto e produtor de seletividade em relação às capacidades de realização de direitos por certas parcelas da população ${ }^{11}$. Os territórios utilizados nas cidades, marcados por desigualdades e injustiças, acabam se tornando "espaços sem cidadãos", logo "a capacidade de utilizar o território não apenas divide como separa os homens, ainda que eles apareçam como se estivessem juntos"12 (p. 59). Nos termos de Milton Santos, delineia-se nas cidades brasileiras a realidade de uma cidadania atrofiada, mutilada, pois "para muitos, a rede urbana existente e a rede de serviços correspondente são apenas reais para os outros. Por isso são cidadãos diminuídos, incompletos"12 (p. 112).

Mais além, sob o ponto de vista das geografias das existências, os territórios onde vivemos também são mais do que um simples conjunto de objetos através dos quais, condizentes ou não com as normas, transcorremos nosso cotidiano. Nesse quesito, as problemáticas "macros" dos modelos de urbanização e gestão das cidades produzidos na agonística do Estado, mercado, corporações e sociedade civil se somam a todo um conjunto de micropolíticas próprias das interrelações sociais cotidianas, transversalizadas por formas de opressões interseccionalizadas (de normatividade, raça, gênero e classe). Para Jorge Luiz Barbosa ${ }^{13}$, a mobilidade socioespacial das pessoas na cidade vai muito além da acessibilidade aos recursos sociais urbanos, e inclusive envolve a urgência de desfazimento de todo um conjunto de geografias de opressões que se desenham nas trajetórias possíveis dessas pessoas nos territórios. Logo, a cidade que é buscada como lugar da multiplicidade, sempre em aberto, dinamizada pelas interrelações cotidianas e, por isso, potente para vivências múltiplas e diversas; também se objetiva estruturalmente como o lugar do sofrimento social.

A sociedade adoece. Essa sociedade é a sua cidade. Tal sobredeterminação põem em xeque as acepções da cidade, da comunidade e do território como entes estáticos, idealizados, ou como 
"sujeitos" naturalmente "bons" e "cuidadores", uma vez que essas concepções não permitem perceber que o sujeito institucionalizado, antes do manicômio, veio justamente daquela realidade socioespacial que, muitas vezes, o adoeceu.

Alinhamo-nos com a - não tão nova - defesa da transformação da cidade como condição para uma política efetiva de cuidado às pessoas em condição de sofrimento mental no país ${ }^{14,15}$. Em nossa perspectiva, desinstitucionalizar, no âmbito da Luta Antimanicomial e RPB, requer disputar a cidade não apenas nas micropolíticas do cotidiano, bem como na esfera de seu planejamento e gestão. Uma vez que a conquista do Direito à Cidade não se qualifica pelo fato do "morar em liberdade" - embora esta seja uma condição mínima para que esse direito se estabeleça. Para cuidar na/com a cidade, é preciso que ela se transforme em um espaço potente de cuidado - o que ultrapassa as fronteiras corporativas da Saúde Mental (mesmo quando se considera o seu sentido ampliado, descentrado, multiprofissional e trans/interdisciplinar). Ainda que o cuidado territorializado seja imprescindível - tensionando, no local, a arena territorial em que se desenrolam os projetos terapêuticos e a vida das pessoas -, urge intervir conjuntamente em uma escala ampliada e em diálogo com o planejamento e gestão da cidade.

Partindo dessa premissa, o presente artigo objetiva refletir sobre os limites e possibilidades de articulação da Luta Antimanicomial com as políticas do urbano nos municípios brasileiros, tomando como foco os Planos Diretores Participativos (PDPs) das cidades, visando potencializar o cuidado antimanicomial em liberdade para as pessoas em sofrimento mental, tal como a garantia de realização e a ampliação de seus direitos.

Com base em uma análise comparada de PDPs dos 15 municípios mais bem pontuados no Ranking CMC 20 de qualidade urbana, elaborado anualmente pela plataforma Connected Smart Cities $^{16}$, pudemos aprofundar a nossa questão norteadora: como as temáticas da Saúde Mental, nos termos da Luta Antimanicomial e RPB, têm sido abordadas no macroplanejamento urbano das cidades no país?

\section{Analisando os planos diretores das cidades: onde está a saúde mental?}

Previsto pela Constituição Federal de 1988, requalificado e ampliado pelo Estatuto da Cidade (EC), em 2001, o PDP é o principal instrumento legislativo de orientação do desenvolvimento, crescimento e ordenamento urbano das cidades. Ele é obrigatório para cidades com população superior a 20 mil habitantes e/ou componentes de regiões metropolitanas, aglomerações urbanas, áreas de especial interesse turístico ou situadas em áreas de influência de empreendimentos de grande impacto ambiental. Trata-se de um instrumento básico das políticas do urbano, estando a ele subordinados: o plano plurianual, as diretrizes orçamentárias e o orçamento anual etc, que devem, por exemplo, incorporar as diretrizes e prioridades por ele definidas ${ }^{17}$. Dada a sua importância, o PDP deve ser revisto a cada 10 anos, sob responsabilidade do governo Executivo $\mathrm{Mu}-$ nicipal vigente na época, de tal forma que sanções previstas pelo EC e pela Lei da Improbidade Administrativa incidem sobre o município que não estiver em conformidade com essa obrigatoriedade.

O PDP é, portanto, um aparato jurídico-urbanístico que, nos moldes atuais, pretende expressar, em grande medida, as conquistas decorrentes de décadas de lutas dos diversos movimentos sociais pela Reforma Urbana e pelo Direito à Cidade no Brasil. Ele é indispensável para, a partir de diretrizes, definição de parâmetros, previsão de instrumentos, planos e metas, articular um amplo conjunto de outros instrumentos de planejamento, controle e gestão da cidade previstos pelo EC, que devem ser organizados estratégica e particularmente de acordo com as realidades locais. Os PDPs buscam, pois, garantir a previsão, direcionamento e segurança jurídico-legislativa de alguns dos princípios considerados estruturantes da democratização da cidade, tais quais: a função social da propriedade urbana, a função social da cidade, o direito à cidade e ao ambiente equilibrado, dentre outros.

Do ponto de vista da esfera pública, é na construção do PDP que a cidade "entra em disputa" pela definição de seus zoneamentos estratégicos, orientações de ordenamento, previsão de planos (incluindo os setoriais), estabelecimento de parâmetros, metas e prazos e, ainda, pela definição de diretrizes, tais quais de mobilidade, saúde, educação, cultura, meio ambiente etc. Ou seja, é com base no PDP que a cidade institucionalmente "se pensa", "se projeta" e "sonha" a partir de um processo longo de construção/revisão, ao perpassar procedimentos de diagnósticos, previsão de cenários e adequação de redações, sempre pretensamente com participação social. Uma vez estabelecido, o plano ganha contorno de Lei, que se processa por audiências públicas para ajustes e para ser votado em seguida. Tal qual se intencio- 
na, o processo de construção dos PDPs deve buscar a configuração de uma arena social ampliada de disputa, como lugar privilegiado da participação social, instaurando uma contenda entre diferentes projetos de cidade (e de viver a, na e com a cidade) em pauta naquela realidade local.

É justamente considerando a obrigatoriedade da ampla participação social na construção dos PDPs (mesmo que, neste artigo, a eficiência da participação não esteja sendo precisada), nos dirigimos rumo a uma investigação sobre as formas com que a temática da Saúde Mental, sob a ótica da Luta Antimanicomial e RPB, se consolidou no texto da Lei desse central instrumento das políticas do urbano.

Para a triagem, análise e comparação dos PDPs de diferentes cidades do país nos referenciamos no ranking de qualidade urbana, elaborado anualmente pela plataforma Connected Smart Cities - que se baseia nos seguintes indicadores: Economia, Educação, Empreendedorismo, Governança, Meio Ambiente, Mobilidade, Acessibilidade, Saúde, Segurança, Tecnologia e Inovação e Urbanismo. O Ranking CMC $20^{16}$ propõe um mapeamento das cidades com maior potencial de crescimento e desenvolvimento urbanos no país. Embora se trate de uma avaliação com interesses corporativos, seu método articula o ranqueamento de diferentes indicadores com vistas ao desenvolvimento, à qualidade de vida e à sustentabilidade das cidades, traçando um panorama comparativo relevante da situação urbana delas - pondera-se no ranqueamento as diferenças em relação ao tamanho das cidades e a situação regional delas.

Das cem cidades ranqueadas, nos ativemos em buscar os PDPs das 15 mais bem colocadas, filtrando buscas nas leituras dos documentos a partir de palavras-chave. Iniciando uma busca preliminar com base no termo "saúde", encontramos um cenário de ampla variedade nas formas de menção, com diferentes tipos de empregos, sentidos e correlações com assuntos diversos. Eles foram classificados de acordo com os seguintes temas:

Direitos constitucionais: saúde (em termos legais); proteção à saúde; saúde humana; saúde ambiental; recuperação da saúde individual e coletiva; necessidades de saúde; promoção da saúde; prevenção da saúde; saúde e cidadania; atenção integral em saúde; boas condições de saúde e segurança; saúde e bem-estar; atenção à saúde; saúde da mulher, das crianças e adolescentes, dos idosos, de pessoas com deficiências e doenças crônicas;
Planejamento e gestão em Saúde: saúde pública; planos setoriais de saúde; padrões da Organização Mundial de Saúde; pesquisa em saúde; informação em saúde; secretaria de saúde; Sistema Único de Saúde (SUS); modelos de atenção à saúde; vigilância em saúde; vigilância epidemiológica; rede de atenção à saúde; Política Nacional de Saúde; novas tecnologias em saúde; gestão da rede municipal de saúde; gestão interfederativa do SUS; Política Municipal de Saúde; gestão participativa; unidades de saúde primárias e secundárias; rede de saúde integrada e hierarquizada; Programa Saúde da Família;

Efeitos em saúde das atividades e do habitar a cidade: saúde dos habitantes vizinhos; risco potencial para a vida e saúde; saúde (em relação a saneamento e poluição); agravos à saúde da população;

Rede de serviços e equipamentos: agentes de saúde; resíduos de saúde; saúde do trabalhador; centros de saúde; hospitais gerais; hospitais especializados; postos de saúde; ambulatórios; saúde bucal.

Desse inventário, destacamos dois detalhes interessantes em PDPs específicos. O primeiro deles, em relação ao PDP da cidade de Niterói-RJ ${ }^{18}$, datado de 2019, que foi o documento que mais mencionou a palavra "saúde" (61 menções) dentre todos os analisados. Embora a maioria dos termos já alinhavados acima sejam também recorrentes nesse outros merecem destaque: atenção integral à saúde da mulher, da criança e do adolescente; saúde e qualidade de vida da população idosa, das pessoas com deficiências e doenças crônicas; planejamento de ações em saúde; três níveis de atenção à saúde; perfil epidemiológico; saúde da família; unidades de saúde especializadas e laboratoriais; e, informações em saúde e pesquisa em saúde.

Segundo, apesar da quantidade expressiva de referências no PDP citado anteriormente, é no PDP de Curitiba-PR ${ }^{19}$, que se trata do único PDP dentre os analisados que faz referência direta aos termos "saúde coletiva" e "determinantes da saúde". O mesmo acontece com o termo "saúde comunitária”, que consta apenas no PDP da cidade de Porto Alegre-RS ${ }^{20}$ - embora este não faça qualquer menção à Saúde Mental.

Do ponto de vista das menções mais rigorosamente vinculadas aos mecanismos de gestão, planejamento e organização das redes em Saúde, é o PDP da cidade do Rio de Janeiro-RJ ${ }^{21}$ que merece maior destaque, por ser o único a evidenciar o termo "plano metropolitano de saúde".

Outros importantes detalhes também devem ser observados, como o caso do PDP de Barue- 
ri-SP, de 2006 (atualizado via Lei Complementar em 2019), que, dentre os analisados, é o único que faz menção ao termo "cidade saudável":

Capítulo II, Art. $9^{\circ}$ - O processo de urbanização do território do Município organiza-se sobre elementos estruturadores e integradores. [...] $\$ 2^{\circ}$. Os elementos integradores são todos aqueles que compõem as funções urbanas agrupados por objetivos, a saber: [...] VI-Cidade Saudável, que conjuga ações preventivas com as curativas no âmbito da saúde, agindo, inclusive, nos fatores ambientais e territoriais que interferem na saúde pública ${ }^{22}$.

Mas qual o lugar dos loucos na cidade?

Analisando mais detalhadamente os mesmos documentos, com base na busca dos termos "saúde mental”, "psicossocial”, "álcool”, “CAPS”, "RAPS", "Centro de Convivência”, "sanatório", "manicômio", "Hospitais Psiquiátricos", "leitos" e "rede", pudemos sistematizar uma tabela (Quadro 1) com os resultados.

Dos 15 PDPs analisados, apenas 6 fazem menção direta a qualquer um dos termos analisados, de forma concernente à temática da Saúde Mental - São Paulo-SP, promulgado em 2014 (1 Lugar no Ranking CMC 20) ${ }^{23}$; Curitiba-PR, promulgado em 2015 (3 Lugar no Ranking CMC 20) ${ }^{19}$; Vitória-ES, promulgado em 2016 (5º Lugar no Ranking CMC 20) 24; Brasília-DF, promulgado em 2009, porém atualizado via Lei Complemen-

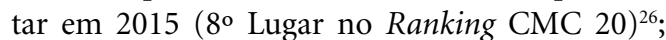
Niterói-RJ, promulgado em 2019 (11º Lugar no Ranking CMC 20) ${ }^{18}$; e Rio de Janeiro-RJ, promulgado em 2011 (12º Lugar no Ranking CMC 20) ${ }^{21}$.

Os termos empregados nesses documentos foram:

Centro de Atenção Psicossocial - CAPS (uma menção, São Paulo-SP): é citado de forma desvinculada de orientações, normativas e/ou diretrizes no PDP. Apenas consta no Quadro 10, anexo à Lei, que inventaria os Equipamentos Urbanos Sociais existentes. CAPÍTULO VIII, Seção I, Parágrafo Único - Os Equipamentos Urbanos e Sociais estão relacionados no Quadro 10 anexo a esta lei $i^{23}$;

Uso de substâncias entorpecentes e álcool (uma menção, Curitiba-PR): Seção VI, Art. 116, $X$ - desenvolver ações de prevenção ao uso de substâncias entorpecentes e álcool, criando métodos e formas de atendimento especializado, objetivando tratamento eficaz, humanizado e no âmbito do Sistema Único de Saúde - SUS ${ }^{19}$;

Sanatório (uma menção, Vitória-ES): o termo é empregado no contexto da Outorga Onerosa do Direito de Construir (OODC). De forma genérica, a OODC pode ser entendida como uma permissão para exercer o direito de construir além do Coeficiente de Aproveitamento (CA) dos terrenos, estipulado pelo Plano Diretor, mediante pagamento. Capítulo II, Seção I, Art. 152: No cálculo do coeficiente de aproveitamento, com exceção das edificações destinadas ao uso residencial unifamiliar, não serão computados: [...] IV - áreas de varandas, contíguas a salas ou quartos, que não ultrapassem: [...] b) 20\% (vinte por cento) da área destinada ao respectivo cômodo em unidades de hospedagem de hotéis, motéis, apart-hotéis, pensões, hospitais, casas de saúde e de repouso, sanatórios e maternidades ${ }^{24}$;

Hospitais especializados em Saúde Mental (uma menção, Brasília-DF): Capítulo VIII, Art. 52: Consideram-se equipamentos regionais os estabelecimentos em que são prestados os serviços das áreas temáticas de educação, segurança pública, saúde, transporte, abastecimento e cultura. [...] III - saúde: hospitais regionais, hospitais especializados em saúde mental e unidades de vigilância sanitária; (Inciso conforme à Lei Complementar $n^{\circ}$ 854, de 2012). Texto original: III - saúde: hospitais regionais e unidades de vigilância sanitária ${ }^{25}$;

Atenção à Saúde Mental (uma menção, Niterói-RJ): Capítulo IV, Art. 253: As diretrizes que integram as politicas de Desenvolvimento Social que incluem a Educação, a Saúde, a Assistência Social, Esporte e Lazer são: [...] VII - ampliar e promover ações intersetoriais voltadas ao fortalecimento da atenção à saúde mental, com ênfase no enfrentamento da dependência de crack e outras drogas, no conjunto de unidades hospitalares da cidade cis; $^{18}$

Centros de Convivência (uma menção, Niterói-RJ): Capítulo VI, Art. 267. São objetivos do Sistema Municipal de Proteção do Patrimônio Cultural: [...] VII - estimular a revitalização de prédios históricos localizados nas ZEPAC-APAU [Zona Especial de Preservação do Ambiente Cultural - Áreas de Preservação do Ambiente Urbano] para atividades voltadas ao idoso, tais como clinicas médicas, centros de convivência e equipamentos de saúde em geral $^{18}$;

Recuperação psicossocial (uma menção, Rio de Janeiro-RJ): SEÇÃO III - DA ASSISTÊNCIA SOCIAL, SUBSEÇÃO II, Art. 267. A Politica de Assistência Social se fará através de programas definidos pelo Conselho Municipal de Assistência Social, que compreenderão a criação, recuperação e manutenção de Centros de Atendimento aos necessitados; o incentivo à construção e manutenção de hospedagem, com programas de recuperação psicossocial, voltados especialmente para a população de rua; a garantia de ampla acessibilidade aos locais de atendimento; e a divulgação ampla dos programas de assistência sociall ${ }^{21}$. 
Quadro 1. Sistematização de menções a termos ligados ao temário da Saúde Mental e Luta Antimanicomial nos Planos Diretores Participativos (PDPs) das 15 cidades mais bem pontuadas no Ranking CMC 20.

\begin{tabular}{|c|c|c|c|c|c|c|c|}
\hline Ranking & Nota & $\begin{array}{l}\text { Porte } \\
\text { da } \\
\text { cidade }\end{array}$ & $\begin{array}{c}\text { Plano } \\
\text { Diretor }\end{array}$ & Promulgação & Menções & $\begin{array}{c}\text { Termo } \\
\text { empregado }\end{array}$ & Texto \\
\hline 1 & 37,901 & $+500 \mathrm{k}$ & $\begin{array}{l}\text { São Paulo } \\
\text { (SP) }\end{array}$ & $\begin{array}{l}01 \text { de Agosto } \\
\text { de } 2014\end{array}$ & $1(31)$ & $\begin{array}{l}\text { Centro de Aten- } \\
\text { ção Psicossocial } \\
\text { (CAPS) }\end{array}$ & $\begin{array}{l}\text { CAPÍTULO VIII, Seção I, Parágrafo } \\
\text { Único - Os Equipamentos Urbanos e } \\
\text { Sociais estão } \\
\text { relacionados no Quadro } 10 \text { anexo a } \\
\text { esta lei }\end{array}$ \\
\hline 2 & 37,224 & $+500 \mathrm{k}$ & $\begin{array}{l}\text { Florianó- } \\
\text { polis (SC) }\end{array}$ & $\begin{array}{l}14 \text { de Janeiro } \\
\text { de } 2014\end{array}$ & 0 & - & - \\
\hline 3 & 36,545 & $+500 \mathrm{k}$ & $\begin{array}{l}\text { Curitiba } \\
\text { (PR) }\end{array}$ & $\begin{array}{l}17 \text { de Dezem- } \\
\text { bro de } 2015\end{array}$ & 1 & $\begin{array}{l}\text { Uso de substân- } \\
\text { cias entorpecen- } \\
\text { tes e álcool }\end{array}$ & $\begin{array}{l}\text { Seção VI, Art. 116, X - desenvolver } \\
\text { ações de prevenção ao uso de substân- } \\
\text { cias entorpecentes e álcool, criando } \\
\text { métodos e } \\
\text { formas de atendimento especializado, } \\
\text { objetivando tratamento eficaz, huma- } \\
\text { nizado e no âmbito do } \\
\text { Sistema Único de Saúde - SUS }\end{array}$ \\
\hline 4 & 36,303 & $+500 \mathrm{k}$ & $\begin{array}{l}\text { Campinas } \\
\text { (SP) }\end{array}$ & $\begin{array}{l}27 \text { de Dezem- } \\
\text { bro de } 2006\end{array}$ & 0 & - & - \\
\hline 5 & 36,251 & $\begin{array}{l}100 \mathrm{a} \\
500 \mathrm{k}\end{array}$ & $\begin{array}{l}\text { Vitória } \\
\text { (ES) }\end{array}$ & $\begin{array}{l}13 \text { de Outubro } \\
\text { de } 2016\end{array}$ & 1 & Sanatório & $\begin{array}{l}\text { Capitulo II, Seção I, Art. 152: No cál- } \\
\text { culo do coeficiente de aproveitamento, } \\
\text { com exceção das edificações } \\
\text { destinadas ao uso residencial unifa- } \\
\text { miliar, não serão computados: IV - } \\
\text { áreas de varandas, contíguas a salas ou } \\
\text { quartos, que não ultrapassem: b) } 20 \% \\
\text { (vinte por cento) da área destinada ao } \\
\text { respectivo cômodo em unidades de } \\
\text { hospedagem de hotéis, motéis, apar- } \\
\text { t-hotéis, pensões, hospitais, casas de } \\
\text { saúde e de } \\
\text { repouso, sanatórios e maternidades }\end{array}$ \\
\hline 6 & 36,107 & $\begin{array}{l}100 \mathrm{a} \\
500 \mathrm{k}\end{array}$ & \begin{tabular}{|l|} 
São \\
Caetano \\
do Sul \\
(SP) \\
\end{tabular} & $\begin{array}{l}9 \text { de Dezem- } \\
\text { bro de } 2015\end{array}$ & 0 & - & - \\
\hline 7 & 35,423 & $\begin{array}{l}100 \mathrm{a} \\
500 \mathrm{k}\end{array}$ & $\begin{array}{l}\text { Santos } \\
\text { (SP) }\end{array}$ & $\begin{array}{l}16 \text { de Julho de } \\
2018\end{array}$ & 0 & - & - \\
\hline 8 & 35,361 & $+500 \mathrm{k}$ & $\begin{array}{l}\text { Brasília } \\
\text { (DF) }\end{array}$ & $\begin{array}{l}25 \text { de Abril } \\
\text { de } 2009, \text { com } \\
\text { complemen- } \\
\text { tar em } 15 \text { de } \\
\text { Outubro de } \\
2015\end{array}$ & 1 & $\begin{array}{l}\text { Hospitais espe- } \\
\text { cializados em } \\
\text { saúde mental }\end{array}$ & $\begin{array}{l}\text { Capítulo VIII, Art. 52, Consideram-se } \\
\text { equipamentos regionais os estabeleci- } \\
\text { mentos em que são prestados os ser- } \\
\text { viços das áreas temáticas de educação, } \\
\text { segurança pública, saúde, transporte, } \\
\text { abastecimento e cultura. III - saúde: } \\
\text { hospitais regionais, hospitais especia- } \\
\text { lizados em saúde mental e unidades } \\
\text { de vigilância sanitária; (Inciso com a } \\
\text { relação da Lei Complementar no } 854 \text {, } \\
\text { de 2012.). Texto original: III - saúde: } \\
\text { hospitais regionais e unidades de vigi- } \\
\text { lância sanitária }\end{array}$ \\
\hline
\end{tabular}


Quadro 1. Sistematização de menções a termos ligados ao temário da Saúde Mental e Luta Antimanicomial nos Planos Diretores Participativos (PDPs) das 15 cidades mais bem pontuadas no Ranking CMC 20.

\begin{tabular}{|c|c|c|c|c|c|c|c|}
\hline Ranking & Nota & $\begin{array}{c}\text { Porte } \\
\text { da } \\
\text { cidade }\end{array}$ & $\begin{array}{c}\text { Plano } \\
\text { Diretor }\end{array}$ & Promulgação & Menções & $\begin{array}{c}\text { Termo } \\
\text { empregado }\end{array}$ & Texto \\
\hline 9 & 34,869 & $+500 \mathrm{k}$ & $\begin{array}{l}\text { Porto } \\
\text { Alegre } \\
(\mathrm{RS})\end{array}$ & $\begin{array}{l}1 \text { de Dezem- } \\
\text { bro } 1999, \text { com } \\
\text { complemen- } \\
\text { tares até } 22 \text { de } \\
\text { Julho de } 2010\end{array}$ & 0 & - & - \\
\hline 10 & 34,608 & $+500 \mathrm{k}$ & $\begin{array}{l}\text { Belo } \\
\text { Horizonte } \\
(\mathrm{MG}) \\
\end{array}$ & $\begin{array}{l}8 \text { de Agosto de } \\
2019\end{array}$ & 0 & - & - \\
\hline 11 & 34,411 & $+500 \mathrm{k}$ & $\begin{array}{l}\text { Niterói } \\
(\mathrm{RJ})\end{array}$ & $\begin{array}{l}3 \text { de Julho de } \\
2019\end{array}$ & 2 & $\begin{array}{l}\text { Atenção à Saúde } \\
\text { Mental; Centros } \\
\text { de Convivência }\end{array}$ & $\begin{array}{l}\text { Capitulo IV, Art. 253: As diretrizes que } \\
\text { integram as políticas de Desenvolvi- } \\
\text { mento Social incluem a Educação, a } \\
\text { Saúde, a Assistência Social, Esporte e } \\
\text { Lazer são: VII - ampliar e promover } \\
\text { ações intersetoriais voltadas ao forta- } \\
\text { lecimento da atenção à saúde mental, } \\
\text { com ênfase no enfrentamento da } \\
\text { dependência de crack e outras drogas, } \\
\text { no conjunto de unidades hospitalares } \\
\text { da cidade; E, Art. 267. São objetivos } \\
\text { do Sistema Municipal de Proteção do } \\
\text { Patrimônio Cultural: VII - estimular } \\
\text { a revitalização de prédios históricos } \\
\text { localizados nas ZEPAC-APAU para } \\
\text { atividades voltadas ao idoso, tais como } \\
\text { clínicas médicas, centros de convivên- } \\
\text { cia e equipamentos de saúde em geral }\end{array}$ \\
\hline 12 & 34,297 & $+500 \mathrm{k}$ & $\begin{array}{l}\text { Rio de } \\
\text { Janeiro } \\
(\mathrm{RJ})\end{array}$ & $\begin{array}{l}1 \text { de Fevereiro } \\
2011\end{array}$ & 1 & $\begin{array}{l}\text { Recuperação } \\
\text { Psicossocial }\end{array}$ & $\begin{array}{l}\text { SEÇÃO III - DA ASSISTÊNCIA SO- } \\
\text { CIAL, SUBSEÇÃO II, Art. 267. A Polí- } \\
\text { tica de Assistência Social se fará através } \\
\text { de programas definidos pelo Conselho } \\
\text { Municipal de Assistência Social, que } \\
\text { compreenderão a criação, recuperação } \\
\text { e manutenção de Centros de Atendi- } \\
\text { mento aos necessitados; o incentivo à } \\
\text { construção e manutenção de hospeda- } \\
\text { gem, com programas de recuperação } \\
\text { psicossocial, voltados especialmente } \\
\text { para a população de rua; a garantia } \\
\text { de ampla acessibilidade aos locais de } \\
\text { atendimento; e a divulgação ampla dos } \\
\text { programas de assistência social }\end{array}$ \\
\hline 13 & 34,214 & $\begin{array}{ll}100 & \mathrm{a} \\
500 \mathrm{k} & \end{array}$ & $\begin{array}{l}\text { Barueri } \\
(\mathrm{SP})\end{array}$ & $\begin{array}{l}10 \text { de Dezem- } \\
\text { bro de } 2004\end{array}$ & 0 & - & - \\
\hline 14 & 34,002 & $+500 \mathrm{k}$ & $\begin{array}{l}\text { Campo } \\
\text { Grande } \\
\text { (MS) }\end{array}$ & $\begin{array}{l}4 \text { de Dezem- } \\
\text { bro de 2018, } \\
\text { com comple- } \\
\text { mentar em } \\
3 \text { de Abril de } \\
2019\end{array}$ & 0 & - & - \\
\hline 15 & 33,557 & $+500 \mathrm{k}$ & Recife (PE) & $\begin{array}{l}14 \text { de Dezem- } \\
\text { bro de } 2018\end{array}$ & 0 & - & - \\
\hline
\end{tabular}

Fonte: Autor, 2020, a partir do Ranking CMC 20; Planos Diretores municipais. 
Gostaríamos de destacar a menção "Atenção à Saúde Mental” no PDP de Niterói-RJ. Em um primeiro momento, ela parece "afeita" aos princípios da Luta Antimanicomial e RPB, porém, nota-se que, apesar de ter sido um PDP promulgado em 2019 (que teoricamente deveria estar adequado à Lei da Reforma Psiquiátrica e demais normativas subsequentes, o que inclui a Portaria GM/MS no 3.088/20112), a adoção do termo citado coloca-se em detrimento do termo "Atenção Psicossocial", tal como foi cunhado pela Portaria que institui as RAPS no Brasil. Contudo, no que diz respeito à linguagem, o mais importante destaque versa sobre o cuidado aos "dependentes de crack e outras drogas", contrastando com o texto da Portaria supracitada, que qualifica a temática em termos de sofrimento ou transtorno mental e com necessidades decorrentes do $u^{2} \mathrm{o}^{2}$. Porém, a informação mais relevante talvez seja o fato de o texto definir uma diretriz específica para a Saúde Mental que, embora ressalve-se o direcionamento intersetorial, orienta as ações para as unidades hospitalares (que entre as quais figura o Hospital Psiquiátrico de Jurujuba - HPJ). Isto diverge do princípio estruturante da RPB, que prioriza os recursos extra-hospitalares.

No caso da menção "Recuperação psicossocial”, no PDP do Rio de Janeiro-RJ, não é irrelevante o fato de a única citação estar enquadrada entre as diretrizes para Assistência Social, com ênfase para as populações em situação de rua, fora do escopo das diretrizes e princípios da Saúde.

Também cabe explicitar a presença do termo "Sanatório" (caso de Vitória-ES), considerado obsoleto, posto que, tal qual "manicômio", passou por longo processo de crítica e é rigorosamente vilipendiado pela Luta Antimanicomial e RPB.

Em suma, de forma geral, podemos constatar não só a timidez e a fragilidade das temáticas da Saúde Mental nos PDPs analisados, como também importante inadequação em relação à linguagem pautada pela Luta Antimanicomial e institucionalizada na RPB - que, lhes são anteriores.

Esse cenário denotaria que os sujeitos e agentes da Luta Antimanicomial e RPB não se fizeram representar nos espaços participativos no processo de elaboração dos PDPs? Ou esses sujeitos e agentes não teriam conseguido força política suficiente na arena participativa para se fazerem representados nos termos das Leis?

Onde está a Luta Antimanicomial no planejamento das cidades?

Como se pensa a implantação das Residências Terapêuticas (RTs) no planejamento do ordenamento urbano-territorial municipal?
Reitera-se: Qual o lugar dos loucos na cidade?

Por mais que pareçam perguntas “novas”, elas já apareceram no cenário nacional em contextos pontuais da luta política em municípios específicos, como nas manifestações ocorridas em Brasília em agosto de 2011. À época, conforme a reportagem do Correio Braziliense, Márcia Guiot Henning, presidente da Anankê, afirmou:

A Reforma Psiquiátrica previu espaços nos centros urbanos para inserção social das pessoas com sofrimento psíquico, acabando com instituições de caráter asilar. Mas quando Plano Diretor foi criado, essa transformação ainda não tinha acontecido. É preciso que isso seja revisto. [...] Não queremos essas pessoas marginalizadas mais uma vez. Não somos hospitais, não produzimos lixo hospitalar, temos atividades psicoterapêuticas, como dança, artes plásticas. Nossa função é diferenciada ${ }^{26}$.

Mas, de fato, quais seriam os limites e possibilidades da Luta Antimanicomial nos PDPs?

\section{Limites e possibilidades para a sáude mental}

Iniciar essa discussão nos obriga a não perder de vista que os PDPs não apenas definem parâmetros urbanísticos, como também versam sobre zoneamentos estratégicos, definição de planos e metas e, principalmente, sobre diretrizes e princípios a serem observados pelos Planos Municipais, que orientam uma ampla gama de outros setores que envolvem o funcionamento das cidades - como a Saúde. Embora caiba destaque que não há quaisquer obrigatoriedades legais em relação à previsão de diretrizes e princípios paras às políticas setoriais municipais, esta tem sido uma prática relativamente consagrada nas últimas décadas, por conta da pressão dos movimentos sociais das cidades e dos novos ativismos urbanos ${ }^{27}$.

Façamos um rápido exercício de conjectura, mesmo que tomemos unicamente o caso das RTs. Existem questões estruturantes que concernem à consolidação e articulação na cidade e que, recorrentemente, enfrentam os seguintes problemas:

As mudanças político-ideológicas entre as gestões e as rupturas e descontinuidades das políticas:

Ao considerar a profunda vinculação da consolidação e funcionamento das RTs à vontade política e aos interesses das gestões vigentes, decorrem-se cenários de insegurança para os moradores quando há mudanças na linha político-ideológica das Secretarias de Saúde e Coordenações de Saúde Mental, que reverberam diretamente no planejamento, bem como na construção e gestão 
das RTs afetando a vida dos moradores. Embora os PDPs não tenham a função de enquadramento da gestão executiva - e sim de definir parâmetros, diretrizes, zoneamentos e instrumentos possíveis para a gestão, sem, com isso, comprometer a governabilidade das gestões -, mas considerando o tempo em que o PDP deve vigorar, a previsão de diretrizes e princípios para as RTs no instrumento tende a acomodar, em alguma medida, as históricas rupturas político-ideológicas nas políticas públicas que marcam as mudanças de gestão no país.

A judicialização como disparadora da demanda:

É comum certa ausência/fragilidade de planejamento a médio e longo prazos para o acolhimento das demandas por RTs, sobretudo nos municípios onde avança a desinstitucionalização. Muitas vezes, a criação de RTs se dá em regimes de emergência, onde o poder executivo consolida as residências conforme o cumprimento de decisões judiciais, com prazos curtos e sem muita flexibilidade em relação à disponibilidade orçamentária. Nesse caso, é factível pensar em diretrizes específicas nos PDPs que prevejam a criação de RTs dentro de zoneamentos estratégicos específicos (como Áreas de Especial Interesse Social, por exemplo), que podem prever parâmetros particulares, mais flexíveis, para a construção e/ ou subsídios específicos para a iniciativa privada local, no sentido do fomento a aluguéis. Da mesma forma que, a previsão de direcionamento de RTs em territórios estratégicos da cidade também podem ampliar exponencialmente o sentido da natureza do serviço. Ainda, é igualmente factível a vinculação de instrumentos de democratização do solo urbano, como o IPTU progressivo e/ou a Outorga Onerosa do Direito de Construir, permitindo acesso a outras possibilidades de recursos para a implementação das residências.

A dificuldade no direcionamento de áreas públicas para a construção de RTs:

A ausência das RTs no macroplanejamento urbano acaba por produzir esse efeito. As demandas, concentradas nas "competências de Saúde", acabam sendo encaradas como questões exclusivas desse setor, tramitando de acordo com as possibilidades da Secretaria de Saúde. Por outro lado, do ponto de vista da intersetorialidade, compreender a construção de RTs como uma questão fundamentalmente habitacional opera efeitos não apenas em termos semióticos - dada a importância do reconhecimento destes sujeitos como o que são: cidadãos com o direito constitucional à moradia -, mas também em termos da solidez de um planejamento intersecretarial. A possibilidade de reconhecer as pessoas egressas dos manicômios como também uma questão de déficit habitacional, tende a estimular certa integração das políticas de Saúde Mental com o Plano Municipal de Habitação, por exemplo - o que induziria previsões não apenas orçamentárias, mas de metas, prazos e instrumentos de gestão compartilhada.

Em contrapartida, muitas vezes a Secretaria de Saúde, presa em suas limitações, acaba optando por garantir o direito via aluguéis. Contudo, não é irrelevante, em parte expressiva das cidades brasileiras, o histórico de instabilidades contratuais no tocante ao descumprimento das responsabilidades que envolvem contratante (poder público) e contratado (proprietário privado) situação que extrapola as competências das Coordenações de Saúde Mental. Isso sem considerar ainda as flutuações próprias do mercado de aluguéis, que afetam de sobremaneira o planejamento orçamentário a longo prazo. Essa se torna uma questão central quando se reivindica uma política massiva de implementação de RTs.

De toda forma, é importante ressaltar que embora existam possibilidades potentes, há muitas outras questões e configurações complexas que envolvem a disputa das políticas do urbano, diretamente ligadas à eficiência dos espaços participativos e a vontade política das gestões executivas. Em suma, é certo que a conquista dos termos da Lei nos PDPs não garante, por si só, a realização do proposto ${ }^{28}$. Não obstante, seguimos tal qual Milton Santos:

Se a lei é realmente cumprida, é outro assunto. [...] A lei não esgota o direito. A lei é apenas o direito positivo, fruto de um equilíbrio de interesses, isto é, de um novo direito. A luta pela cidadania não se esgota na confecção de uma lei ou da Constituição porque a lei é apenas uma concreção, um momento finito de um debate filosófico sempre inacabado ${ }^{11}$ (p. 80).

\section{Considerações finais}

Ao longo deste artigo, pudemos refletir sobre o papel das cidades em relação ao cuidado antimanicomial em liberdade e à atenção psicossocial das pessoas em sofrimento mental, onde buscamos debater a importância da participação da Luta Antimanicomial na elaboração dos PDPs das cidades no Brasil. A desinstitucionalização e RPB, como pressupõem orientar o cuidado e atenção psicossocial pensando a cidade, impli- 
cam justamente na necessidade de a cidade pensá-las. Nos documentos analisados, nem a Luta Antimanicomial, nem a RPB e, muito menos, os princípios da desinstitucionalização, estão articulados de forma minimamente satisfatória com o planejamento urbano estrutural das cidades. $\mathrm{O}$ que apresentamos em termos empíricos deve ser problematizado no sentido de avançarmos e ocuparmos as políticas do urbano, não como um fim em si, posto que as arenas públicas, privadas e do comum respondem a determinações, processos e correlações de forças outras ${ }^{29,30}$. Ainda assim, esse é um caminho necessário e inadiável para que a cidade se concretize como um espaço convivial ${ }^{31}$, de cuidado e produção de saúde.

Contudo, é importante considerar que as cidades analisadas a partir do ranking de qualidade urbana são majoritariamente localizadas na região geoeconômica centro-sul brasileira (região concentradora dos maiores níveis de densidade técnica e fluxo de capitais, pessoas e informação). A única exceção foi a cidade do Recife-PE, justamente ocupando a $15^{\text {a }}$ posição do referido ranking, mas que ainda assim se destaca como centralidade nacional. A amostragem aqui analisada não abarca, portanto, a realidade de outras cidades deslocadas das centralidades nacionais e que, no entanto, possuem experiências particulares e protagonismo na Luta Antimanicomial - como Bauru-SP, Barbacena-MG, entre outras.

Ainda que não tenham sido analisados no escopo deste artigo, identificamos alguns casos que preveem propostas concretas para a organização da Saúde Mental na cidade via PDP. É o caso de Janaúba-MG, que compõe a região intermediária de Montes Claros-MG. O seu PDP, datado de 2007, afirma, na Seção II ("Da Política Municipal de Saúde”), Subseção I (“Dos processos gerais”), no Art. 136:
São diretrizes da Política de Saúde: [...] VI. Obter um grau de resolutibilidade nos serviços que considere a racionalização com os custos otimizados dos serviços, assim como a efetividade $e$ qualidade na resposta terapêutica, incluindo o livre acesso às diversas alternativas de tratamento existentes e à reversão do modelo hospitalocêntrico ${ }^{32}$.

Por último, destacamos que, no que tange aos "direitos da cidade" (ou seja, da liberdade e capacidade individual de exercício e uso dos recursos sociais urbanos), a perspectiva do Direito à Cidade os extrapola para afirmar a possibilidade de reinvenção da cidade como radicalização do exercício da liberdade e como horizonte para a tomada de consciência e de poder das pessoas. $\mathrm{O}$ Direito à Cidade é, portanto, a luta pelo direito à vida urbana renovada, à apropriação da cidade como valor de uso e lugar do encontro vitalizante, vislumbrando a cidade como obra (em termos de atividade participante). Direito à liberdade, à individualização na socialização, ao habitat e ao ha$\operatorname{bitar}^{33}$ (p. 134). Não se trata de um direito individual, ou um direito a ser institucionalizado pelo Estado, mas de uma plataforma ético-política a ser constantemente encampada, (re)construída e (re)conquistada pelas lutas populares contra a lógica mercantilizadora da cidade e da vida:

$O$ direito à cidade é muito mais que a liberdade individual de ter acesso aos recursos urbanos: é um direito de mudar a nós mesmos, mudando a cidade. [...] A liberdade de fazer e refazer as nossas cidades, e a nós mesmos, é, a meu ver, um dos nossos direitos humanos mais preciosos e ao mesmo tempo mais negligenciados ${ }^{34}$ (p. 38).

Avante Luta Antimanicomial, ocupemos os Planos Diretores das cidades... pelo Direito à Cidade Antimanicomial! 


\section{Referências}

1. Brasil. Lei n ${ }^{\circ} 10.216$, de 6 de abril de 2001. Diário Oficial da União 2001; 9 abr.

2. Brasil. Ministério da Saúde (MS). Portaria GM/MS no 3.088, de 23 de dezembro de 2011. Brasília: MS; 2011.

3. Nicácio F, organizador. Desinstitucionalização. São Paulo: Hucitec; 2001.

4. Amarante P. Saúde mental e atenção psicossocial. Rio de Janeiro: Editora Fiocruz; 2007.

5. Costa-Rosa, A. Atenção Psicossocial além da Reforma Psiquiátrica: contribuições a uma Clínica Crítica dos processos de subjetivação na Saúde Coletiva. São Paulo: Editora UNESP; 2013.

6. Rotelli F, Leonardis O, Mauri D. Desinstitucionalização, uma outra via: a reforma psiquiátrica italiana no contexto da Europa Ocidental e dos "países avançados". In: Nicácio F, organizador. Desinstitucionalização. São Paulo: Hucitec; 2001. p. 17-59.

7. Scarcelli IR. Entre o hospício e a cidade: dilemas no campo da saúde mental. São Paulo: Zagodoni; 2011.

8. Harvey D. A produção capitalista do espaço. São Paulo: Annablume; 2005.

9. Kowarick L. Espoliação urbana. São Paulo: Paz e Terra; 1979.

10. Santos M, Silveira ML. O Brasil: território e sociedade no início do século XXI. $6^{\mathrm{a}}$ ed. Rio de Janeiro: Record; 2004.

11. Carlos AF. Dinâmica urbana e metropolização: desvendando os processos espaciais. In: Ferreira A, Rua J, Marafon GJ, Silva ACP, organizadores. Metropolização do espaço: gestão territorial e relações urbano-rurais. Rio de Janeiro: Consequência; 2013.

12. Santos M. O espaço do cidadão. São Paulo: Nobel; 1987.

13. Barbosa JL. A mobilidade urbana como expressão do direito à metrópole. In: Limonad E, Castro ER, organizadores. Um novo planejamento para um novo Brasil? Rio de Janeiro: Letra Capital; 2014.

14. Amarante P, Torre EHG. "De volta à cidade, sr. cidadão!” - reforma psiquiátrica e participação social: do isolamento institucional ao movimento antimanicomial. Rev Administração Publica 2018; 52(6). [acessado 2020 ago 29]. Disponível em: https://doi. org/10.1590/0034-761220170130.

15. Venturini E. A linha curva: o espaço e o tempo da desinstitucionalização. Rio de Janeiro: Fiocruz; 2016.

16. Ranking Connected Smart Cities 2021. [acessado 2020 ago 29]. Disponível em: http://ranking.connectedsmartcities.com.br/resultados-cidade.php?sel=1

17. Brasil. Estatuto da Cidade: Guia para implementação pelos municípios e cidadãos. $2^{\text {a }}$ ed. Brasília: Câmara dos Deputados, Coordenação de Publicações; 2002.

18. Brasil. Lei Municipal no 3.385/2019. Aprova a Política de Desenvolvimento Urbano do Município, institui o Plano Diretor de Niterói e revoga as Leis no 1157 de 29/12/1992; Lei no 1.254 de 28 de dezembro de 1993; $\mathrm{n}^{\circ} 2.123$ de 04/02/2004; Parágrafo $3^{\circ}$ do Art. 17, da Lei $n^{\circ} 3.061$ de 03 dezembro de 2013 e Lei no 2.023 de 19 de setembro de 2002. Rio de Janeiro: Prefeitura Municipal de Niterói; 2019.
19. Brasil. Lei no 14.771, de 17 de dezembro de 2015. Dispõe sobre a Revisão do Plano Diretor de Curitiba de acordo com o disposto no art. 40, $\$ 3^{\circ}$, do Estatuto da Cidade, para orientação e controle do desenvolvimento integrado do município. Paraná: Prefeitura Municipal de Curitiba; 2015.

20. Brasil. Plano Diretor de Desenvolvimento Urbano Ambiental (PDDA). Rio Grande do Sul: Prefeitura Municipal de Porto Alegre; 2011.

21. Brasil. Lei Complementar $n^{\circ} 111$ de $1^{\circ}$ de fevereiro de 2011. Dispõe sobre a política urbana e ambiental do município, institui o plano diretor de desenvolvimento urbano sustentável do município do rio de janeiro e dá outras providências. Rio de Janeiro: Prefeitura Municipal do Rio de Janeiro; 2011.

22. Brasil. Lei Complementar $n^{\circ} 245$, de 18 de dezembro de 2009. Altera e consolida a lei complementar $n^{\circ} 175$, de 12 de dezembro de 2006. São Paulo: Prefeitura do Município de Barueri; 2009.

23. Brasil. Lei no 16.050, de 31 de julho de 2014. Aprova a Política de Desenvolvimento Urbano e o Plano Diretor Estratégico do Município de São Paulo e revoga a Lei no 13.430/2002. São Paulo: Prefeitura do Município de São Paulo; 2014.

24. Brasil. Lei n $n^{\circ}$ 6705. Institui o Plano Diretor Urbano do município de Vitória e dá outras providências. Espírito Santo: Prefeitura Municipal de Vitória; 2016.

25. Brasil. Lei Complementar no 803, de 25 de abril de 2009. Aprova a revisão do Plano Diretor de Ordenamento Territorial do Distrito Federal (PDOT) e dá outras providências. Distrito Federal: Prefeitura Municipal de Brasília; 2009.

26. Atenção à saúde mental está comprometida no Distrito Federal. Seção Cidades. Correio Braziliense. 2011 Jul 10. [acessado 2020 ago 29]. Disponível em: https://www.correiobraziliense.com.br/app/noticia/ cidades/2011/07/10/interna_cidadesdf,260546/atencao-a-saude-mental-esta-comprometida-no-distritofederal.shtml

27. Prist AH, Bucci MPD. Direito à Cidade e esfera pública: entre a participação política e a renovação jurídico-urbanística. Rev Cad Metrópole 2021; 23(51). [acessado $2021 \mathrm{fev}$ 13]. Disponível em: https://doi. org/10.1590/2236-9996.2021-5108.

28. Fernandes E. Estatuto da Cidade, mais de 10 anos depois: razão de descrença, ou razão de otimismo? Rev UFGM 2013; 20(1). [acessado 2019 maio 27]. Disponível em: https://periodicos.ufmg.br/index.php/revistadaufmg/article/view/2681/1547

29. Pereira EM. Como anda a participação? As condições para a elaboração de Planos Diretores Participativos. Rev Bras Estud Urbanos Reg 2017; 19(2). [acessado 2017 set 18]. Disponível em: https://www.redalyc.org/ articulo.oa?id $=513954272003$

30. Orozco ATM. Entre o público e o privado: intermediação de interesses no processo de revisão do Plano Diretor da cidade de Niterói/RJ. In: III CONGEO Congresso Brasileiro de Geografia Política, Geopolítica e Gestão do Território, 2018, Niterói. Caderno de Resumos do III CONGEO (Congresso Brasileiro de Geografia Política, Geopolítica e Gestão do Território). REBRAGEO: Niterói; 2018. 
31. Lima IG. A metrópole convivial: por uma geografia social crítica dos commons. In: Ferreira A, Rua J, Mattos RC, organizadores. Produção do espaço: emancipação social, o comum e a "verdadeira democracia". Rio de Janeiro: Consequência; 2019.

32. Brasil. Lei $n^{\circ} 1.744 / 2007$. Dispõe sobre a política de desenvolvimento e de expansão urbana do município de janaúba, institui o plano diretor democrático de desenvolvimento sustentável e dá outras providências. Minas Gerais: Prefeitura Municipal de Janaúba; 2007.

33. Lefebvre H. O Direito à Cidade. Tradução de Rubens Eduardo Frias. São Paulo: Centauro; 2001.

34. Harvey D. O direito à cidade. Rev Piaui 2013; 82. [acessado 2015 fev 8]. Disponível em: https://piaui. folha.uol.com.br/materia/o-direito-a-cidade/

Artigo apresentado em 31/10/2020

Aprovado em 14/10/2021

Versão final apresentada em 16/10/2021

Editores-chefes: Romeu Gomes, Antônio Augusto Moura da Silva 